Journal of Science
http://dergipark.gov.tr/gujs

\title{
A Comprehensive Thermophysiological Comfort Analysis of Breathable Membrane Laminated Fabrics
}

\author{
Caglar SIVRI* \\ Bahcesehir University, Management Engineering Department, 34349, İstanbul, Turkey
}

\author{
Highlights \\ - Analysis for Thermophysiological analysis of breathable membrane laminated fabrics. \\ - Non-destructive approach to minimize material consumption in sustainable way. \\ - Selection of ideal type of fabric to be used in the design of breathable waterproof structures.
}

\begin{tabular}{l} 
Article Info \\
\hline Received: 25 Sep 2020 \\
Accepted: 19 May 2021 \\
Keywords \\
Comfort \\
Breathable fabrics \\
Membranes \\
Thermophysiology \\
Sem analysis
\end{tabular}

\section{INTRODUCTION}

Many applications in technical textiles have been considered useless just because they can't meet the comfort requirements of the users even though they reach their targeted function [1]. Similar problems in the field of breathable waterproof fabrics are faced likewise. In fact, in the case of cold-weather clothing for instance, if they can't meet the required performance criteria, the body's temperature drops below normal resulting with situations from severe illness to death [2]. The first effective breathable, waterproof fabric in the 1940s is Ventile which was developed for military purposes. The best type of long-staple cotton is chosen so that very small gaps remain between the fibers. When the fabric surface is wetted with water, cotton fibers swell transverse direction, which reduces the pore sizes in the fabric and the high pressure required for liquid penetration [3]. The first and possibly best recognized microporous membrane is known as Gore-Tex (http://www.gorefabrics.com) with polytetrafluoroethylene (PTFE) content developed and promoted by W Gore in 1976 [4]. In 2006, Sympatex company produced the highest water vapour permeable membrane in the world having $1.5 \mathrm{Ret}\left[\mathrm{m}^{2} . \mathrm{Pa} / \mathrm{W}\right]$ value with copolyetherester content [5]. As can be seen, in recent years, the work in this area was mainly concentrated on the improvement of water vapour permeability rather than waterproofness. Today we have reasonably and/or highly breathable materials thanks to advanced coating and lamination techniques [6]. Besides, new polymers have extended the possibilities of developing new and competitive clothing. Apart from material technologies, comfort testing is a critical point in the development of breathable fabrics. In this context, Kaplan and Okur have pointed out that to investigate the thermal comfort performances of fabrics and garment systems, besides physiological changes in the human body, heat and mass transfer mechanisms ensuring these changes 
should also be analysed [7]. In another study, it was pointed out that the results of the physical methods must also be validated by the perception of the human in wearer trials to achieve a real comfort perception [8]. Shishoo, R. has also supported this fact by proclaiming that wearer trials are required to calibrate laboratory procedures [9]. Researchers also reported that determination of fabric resistance to surface wetting via spray test, determination of resistance to water via hydrostatic pressure testing, the resistance to water vapour permeability and determination of water repellency of fabrics via rain-shower test as essential considerations in comfort testing of breathable fabrics [10-13]. There are numerous techniques available to analyse heat and moisture transfer in textile clothing that have already been mentioned in other studies. But few of them are done in a non-destructive way [14-15]. Coated and laminated fabrics are high value-added products as they comprised of a few layers of polymer coating or a membrane/fabric/adhesive, etc. A common approach in breathable fabric testing is preparing samples in defined sizes by cutting from roll fabrics. When several cycles or repeats in testing procedures were considered, these processes become high costly, because one needs to cut new samples for each cycle. On the other hand, there are nondestructive testing instruments and methods available to overcome this cost problem [16-17]. Permetest, which was described in detail below, is one of these instruments testing in a non-destructive manner. Permetest has been used to characterize water vapour permeability or in other words 'breathability' of textile fabrics for a long time [18]. The instrument measures the water vapour transmission value according to the ISO 11092 standard [19]. It is also a user-friendly instrument even non-textile experts or customers can measure and compare the breathing performance of the textile fabrics.

Some experimental data from the relevant studies have also been found and compared with the parameters investigated within this study. Kaynakl1 and Karadeniz have determined the thermal comfort level for required body temperatures and ambient conditions. The study results have shown that people must wear clothing having low insulation resistance for feeling comfortable in high relative humidity ambiences [20]. Huang has pointed out that the usage of multilayer clothing is better than single layer clothing in that the insulation provided by several layers can be easily adjusted, but the water vapour transfer mechanism should be maintained and work properly [21]. Ruckman has stated that the greater the wind speed leads to the greater the water vapour transfer, therefore windy conditions must also be considered in the development of membrane laminated waterproof-breathable multi-layer fabrics [22]. Researchers have also studied the effect of thickness and air gap on water vapour permeability of breathable waterproof fabrics. The study performed by Razzaque et al. revealed that water vapour permeability of multi-layered laminated fabrics increased with decreasing fabric thickness [23].

In this study, a comprehensive thermophysiological comfort analysis of breathable membrane laminated fabrics was carried out using non-destructive testing methods and instruments. To this aim, water resistance, water vapour permeability and air permeability of breathable fabric samples were assessed and the effect of the air gap between body and clothing on water vapour resistance was also simulated using ring apparatus tailored for this study.

\section{MATERIAL METHOD}

In this study, some parameters affecting the comfort properties of laminated semi-permeable textile fabrics were investigated by including two different types of semi-permeable membrane types. Following this scope, the factors affecting the basic comfort characteristics of the semi-permeable membranes, such as water vapour permeability and air permeability, were examined through the measurements.

This study focuses on the comfort properties of laminated semi-permeable textile fabrics. In addition to laminated fabrics, textile fabrics coated for comparison are also included in the study. 12 semi-permeable composite fabric samples of different types that are laminated with a membrane or coated with a polymer sheet are included in the scope of the study. Fabric samples mainly consist of laminated fabrics. Coated fabrics are also included for comparison purposes. Fabrics have been supplied from the world's leading high-performance fabric manufacturers such as W Gore, DuPont, Sympatex, Concordia Textiles, Astona, Aliachem (Table 1). 
Table 1. Technical information of semi-permeable fabrics of the study

\begin{tabular}{|c|c|c|c|c|c|}
\hline Name & Weave Type & Membrane/Coating Type & Technique & $\begin{array}{l}\text { Thickness } \\
(\mathrm{mm})\end{array}$ & $\begin{array}{l}\text { Weight } \\
\left(\mathrm{g} / \mathrm{m}^{2}\right)\end{array}$ \\
\hline $\begin{array}{l}\text { Basic } \\
\text { Hydrophilic }\end{array}$ & $\begin{array}{l}\text { Polyester } \\
(\text { PES)/Twill }\end{array}$ & $\begin{array}{l}\text { PTFE Micro- } \\
\text { porous+Hydrophilic }\end{array}$ & Coated & 0.36 & 185 \\
\hline $\begin{array}{l}\text { Basic Micro- } \\
\text { porous }\end{array}$ & PES/Plain & PU Micro-porous & Laminated & 0.40 & 113 \\
\hline Alkana & Nylon/Plain & PU Nonporous/Hydrophilic & Coated & 0.17 & 124 \\
\hline Ulfa-Porotex & PES/Plain & $\begin{array}{l}\text { PU Micro-p or ou s } \\
\text { /Hydrophilic }\end{array}$ & Coated & 0.31 & 140 \\
\hline Basic Nylon & Nylon/Plain & Nonporous/Hydrophilic & Coated & 0.26 & 115 \\
\hline Teflon & PES/Plain & PTFE Micro-porous & Laminated & 0.27 & 123 \\
\hline Goretex-XCR & $\begin{array}{l}\text { Pleated } \\
\text { PES/Twill }\end{array}$ & PTFE Micro-porous & Laminated & 0.38 & 162 \\
\hline Sympatex 3V & PES/Plain & $\begin{array}{l}\text { Monolithic-Copolymer } \\
(70 \% \\
\text { PES, 30\% }\end{array}$ & Laminated & 0.36 & 179 \\
\hline $\begin{array}{l}\text { Polymax } \\
\text { Neopren }\end{array}$ & PES/Plain & $\begin{array}{l}\text { Polychloroprene } \\
\text { /Hydrophilic }\end{array}$ & Laminated & 0.34 & 131 \\
\hline $\begin{array}{l}\text { Sympatex } \\
\text { Neopren }\end{array}$ & PES/Plain & $\begin{array}{l}\text { Polychloroprene/Hydrophili } \\
\text { c }\end{array}$ & Laminated & 0.44 & 173 \\
\hline $\begin{array}{l}\text { Windstopper } \\
\text { Soft Shell }\end{array}$ & $\begin{array}{l}\text { Stretch } \\
\text { PES\&PES } \\
\text { Fleece/Knit } \\
\end{array}$ & PTFE Micro-porous & Laminated & 1.53 & 351 \\
\hline Omnistorm & $\begin{array}{l}\text { Pleated } \\
\text { PES/Plain }\end{array}$ & $\begin{array}{l}\text { 73\% PA\&11\% PU\& 16\% } \\
\text { Acrylic/Hydrophilic }\end{array}$ & Laminated & 0.50 & 203 \\
\hline
\end{tabular}

In this study, water vapour permeability of semi-permeable textile fabrics laminated with hydrophilic and/or microporous membranes and other parameters affecting this parameter such as thickness, air gap, weight, the moisture content in material were analysed under constant laboratory conditions. Also, by measuring the air permeability for each fabric, information about the character of the breathable semi-permeable fabric tested was obtained. Impact penetration - water resistance test was carried out to evaluate the waterproofness ability of the fabrics. A plastic ring apparatus also designed and used to simulate the air gap between body and clothing. Finally, the morphology of the samples was characterized using scanning electron microscopy. The thickness of the fabric samples was measured using the Alambeta instrument (Sensora Company, Chechia).

While performing these tests, non-destructive test devices and methods that do not damage fabrics in any way were used. Testing conditions were given in Table 2 . 
Table 2. Testing conditions

\begin{tabular}{|c|c|c|c|}
\hline \multirow{2}{*}{ Testing Conditions } & \multicolumn{3}{|c|}{ Test Instruments and Apparatus } \\
\hline & Permetest & Fx-Textest & $\begin{array}{l}\text { Water } \\
\text { Resistance }\end{array}$ \\
\hline Test numbers & 10 & 10 & 10 \\
\hline The Comfort & rWater & rAir & Water \\
\hline Measured by the Instrument & permeability & Permeability & proofness \\
\hline Laboratory Conditions & \multicolumn{3}{|c|}{$65 \% \pm 2$ Relative humidity and $20 \pm 2^{\circ} \mathrm{C}$ temperature } \\
\hline
\end{tabular}

\subsection{Measurement of $R_{\mathrm{et}}$ Value According to ISO 11092 Standard}

An instrument called Permetest was used to measure water vapour transmission to obtain a standard value according to ISO 11092. This instrument and standard are used in the thermophysiological analysis of textile fabrics commonly (Figure 1). A reference fabric was used to determine water vapour resistance. The $\mathrm{C}$ (permeability constant) value in the laboratory is determined in $\operatorname{Ret}\left[\mathrm{m}^{2} . \mathrm{Pa} / \mathrm{W}\right]$ according to ISO 11092 using this reference sample [24]. Finally, the Ret value of the fabric can be calculated by putting the $\mathrm{C}$ value in the formula given below considering other parameters in the formula [25]

$\operatorname{Ret}=C(1-\phi)\left(\frac{1}{q_{h s}^{\prime}}-\frac{1}{q_{h 0}^{\prime}}\right)\left[m^{2} \cdot P a / W\right]$

where

C: Permeability constant within the testing laboratory,

$\varphi$ : Relative Humidity in \% within the testing laboratory,

q'h0: Heat flow on the measuring head without sample,

q'hs: Heat loss on measuring head that covered with a sample.

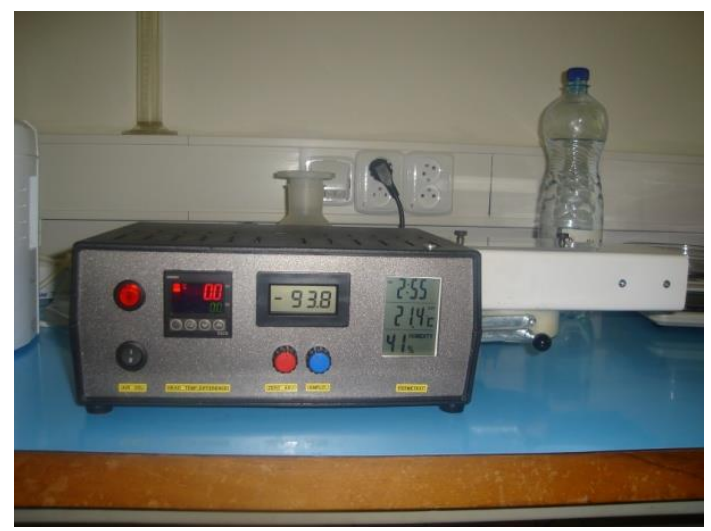

Figure 1. The permetest instrument

Also, relative water vapour permeability (Rwvp) can be calculated according to the following formula:

$R w v p=\frac{q_{h s}^{\prime}}{q_{h 0}^{\prime}} \cdot 100 \%$

where

q'h0 is the heat flow on the measuring head without a sample,

q'hs is the heat loss that is resultant in liquid when the measuring head is covered by a sample. 
Heat flow (q'h0) is the amount of heat that is transferred per unit of time in some material. It might be directly affected by changing weather conditions such as windy air or rainy air. Heat loss (q'hs) is the release of heat from the body especially an item of clothing is worn.

\subsection{Measurement of Air Permeability Value Using Fx-Texttest 3300 Instrument}

Air permeability of the fabric samples within the study was measured according to TS EN 9237 Standard using Fx-Text 3300 instrument (Figure 2). Air permeability measurement was carried out 10 times for each sample, under 100, 200 and 500 Pascal pressure differences at $20 \mathrm{~cm}^{2}$ area were applied for 1 minute [26].

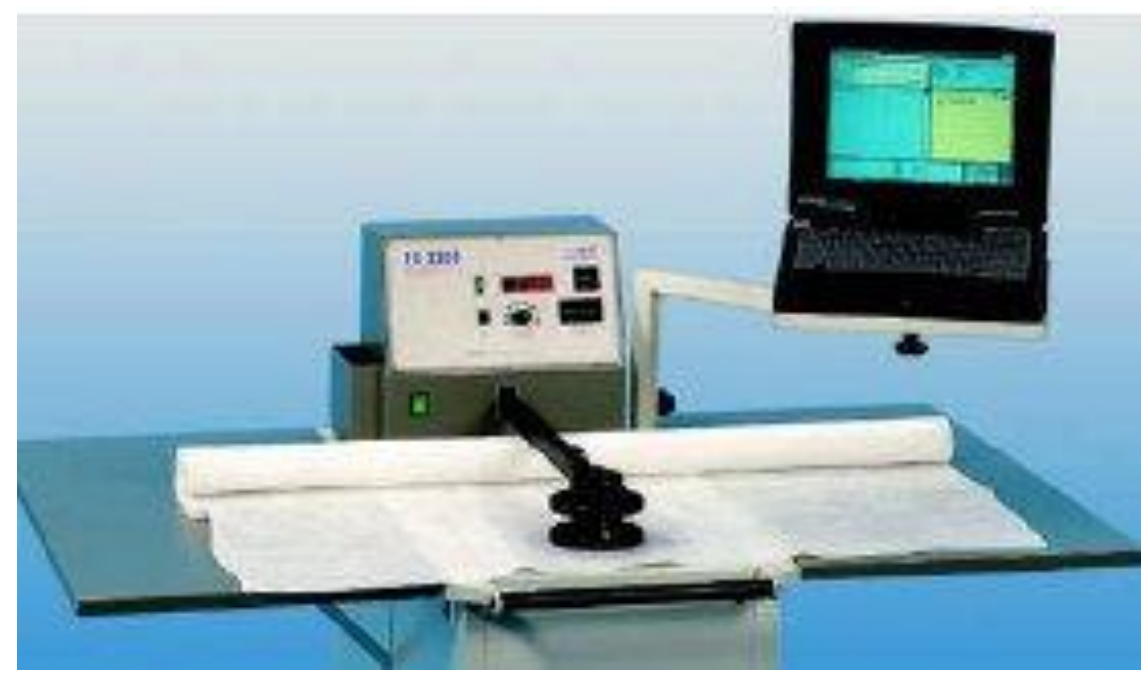

Figure 2. Fx-texttest air permeability tester

\subsection{Measurement of Water Resistance Using Impact Penetration Test Apparatus}

In this study, the water-resistance: impact penetration test was performed according to AATCC 42-200 to measure the water resistance of the samples or the degree of allowing water penetration. The general purpose of the apparatus used for this test is to measure the rain resistance of garments (Figure 3). In principle, the hopper pores of the funnel are opened at a distance of $60 \mathrm{~cm}$ from the back of the sample, whose background is supported with a drying paper and tightly clamped in the nipping area, and a certain volume of water in it is sprayed on the sample. After running out of water in the funnel, excess water on the test specimen is removed so that it does not drip on the background of the sample. Then, the drying paper clamped to the grapples on the back of the fabric is immediately weighed on the precision scale and the water-resistance degree is determined from the difference between the present weight and the dry weight [27].

Samples were prepared by this test standard and this test was repeated for each sample. Measurement of water resistance was repeated 10 times.

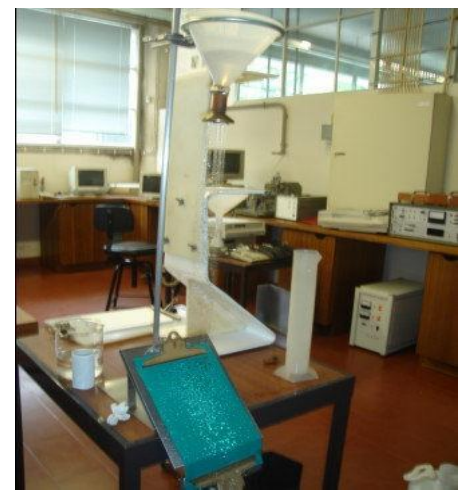

Figure 3. Impact penetration test apparatus for waterproofness 


\subsection{Scanning Electron Microscopy}

Samples were examined by using Vega Tescan brand Scanning Electron Microscope (SEM) to get information about the specific parameters such as layer number of the fabrics in the study, prominent features of the layers, their size, and the way they are bonded. The images were taken under $200 \mathrm{X}$ and $2 \mathrm{kX}$ magnification rates.

\subsection{Ring Apparatus Designed and Used to Simulate the Air Gap Between Body and Clothing}

For this simulation process, 3 plastic rings of $6 \mathrm{~mm}, 12 \mathrm{~mm}$ and $20 \mathrm{~mm}$ lengths and $80 \mathrm{~mm}$ width were designed and used to simulate and determine the effect of air gap between body and clothing during water vapour permeability measurement (Figure 4). These rings of 3 different lengths and the same width were placed between the sample to be measured and the measuring head of the Permetest device and the air gap was successfully simulated. Since the diameter of the measuring head of the Permetest device is $80 \mathrm{~mm}$, the diameters of the tailored rings are critical here. Because, if the diameters are different, for example, if the ring diameter is smaller than the diameter of the measuring head of the device, the mass transmitted from the remaining gap will create a large variation in the measurement. If the ring diameter is assumed to be greater than the diameter of the measuring head of the device, there will be a variation as it is not compactly placed between the wind tunnel and the fabric measuring head.

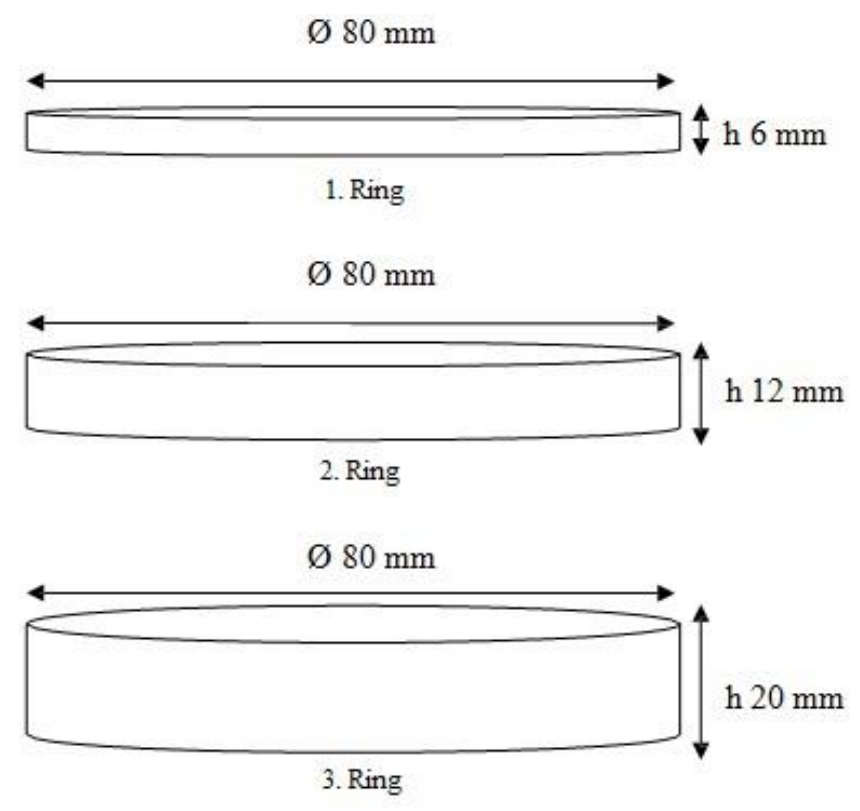

Figure 4. Ring apparatus simulating the air gap between body and clothing

\section{THE RESEARCH FINDINGS AND DISCUSSION}

\subsection{Water Vapour Permeability Measurement Results}

The general trend for breathability is that the water vapour permeability is mostly higher than the Ret value. It can be seen from Figure 5 that the Teflon (PTFE) membrane laminated semi-permeable fabric has the highest water vapour permeability while having the lowest Ret value. Fabrics such as Basic Microporous, Basic Nylon and Polymax are behaving on the contrary to this trend as their Ret value lower than their water vapour permeability in $\%$ and especially the first two are only suitable for use in short-lasting activities requiring low performance. Polymax, however, has a reasonable level of vapour permeability despite its poor Ret value and it can be used in moderate performance activities. Besides, due to its hydrophilic character, it can also be easily used in medical applications as an alternative. The results obtained from water vapour permeability measurements within this study have strongly supported one of the most important study results that was carried out by Ruckman in waterproof breathable fabrics area 
[28]. Ruckman has reported that the rates of water vapour transfer are ranked as follows, microfibre fabrics; cotton ventiles, PTFE-laminated fabrics; poromeric polyurethane-laminated fabrics, hydrophilic-laminated fabrics; and polyurethane-coated fabrics. In this study, PTFE laminated Teflon fabric outperformed in terms of water vapour permeability as present study did not include microfiber fabrics. Besides, the present study provided Ret results, in other words resistance against water vapour permeability, along with water vapour permeability results as a basic difference and novelist addition to Ruckman's study. As a result, PTFE laminated Teflon fabric had the lowest Ret value. This result shows that Teflon fabrics outperformed in terms of breathability.

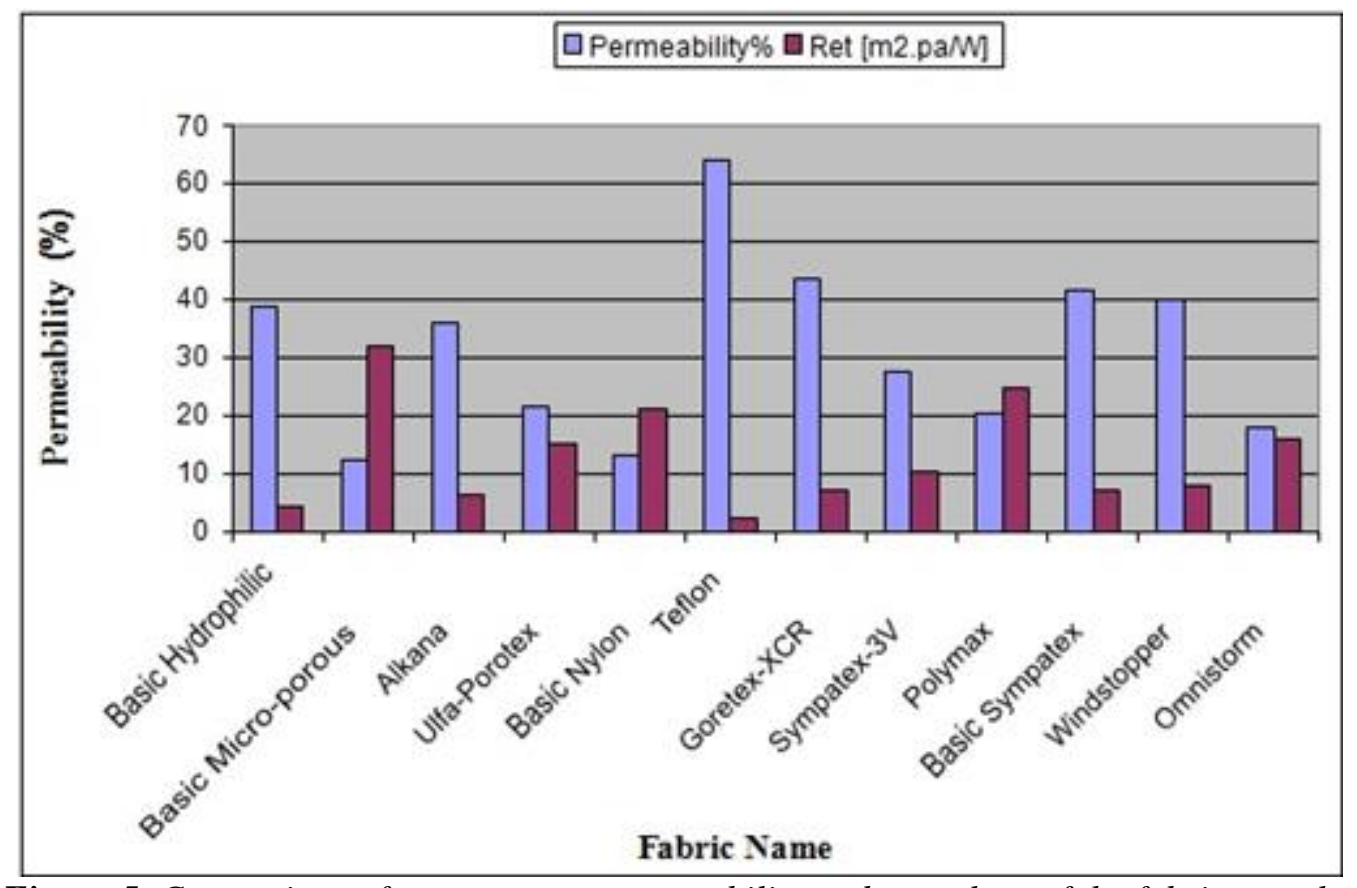

Figure 5. Comparison of water vapour permeability and ret values of the fabric samples

\subsection{The Effect of Fabric Thickness on Water Vapor Permeability}

Figure 6 shows the effect of fabric thickness on the water vapour permeability. Thickness measurements were carried out for 100\% PP uniform woven fabric samples of 1 layer, 2 layers, 3 layers and 4 layers. Fabric water vapour permeability decreases significantly as its thickness increases. This leads to an increase in Ret value and it decreases the breathability. Except in some special cases, this is valid for all fabric types.

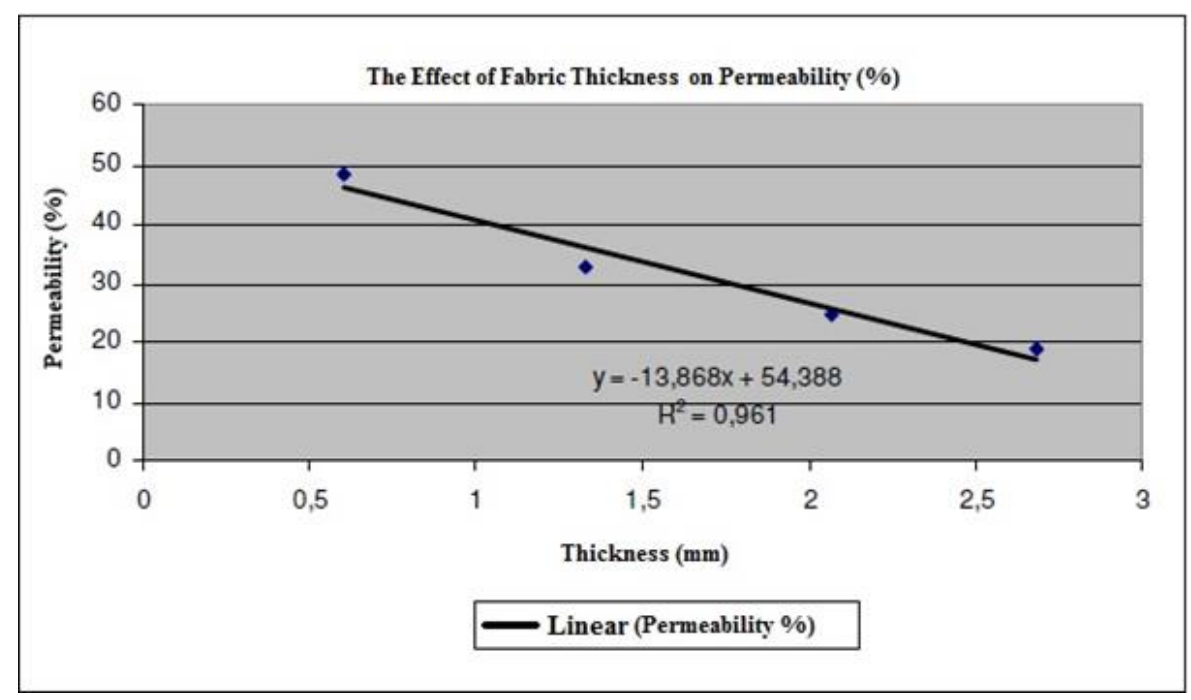

Figure 6. Effect of fabric thickness on water vapor permeability 


\subsection{Air Permeability Measurement Results}

As a result of measurements, even the least amount of air $(1 / \mathrm{m} 2 / \mathrm{h})$ didn't pass through semi-permeable fabric samples in other words the fabrics were found to be air-proof. This means that the pores of the fabrics or solid polymeric structure are small or ducted enough to prevent the passage of air.

\subsection{Water Resistance Measurement Results}

Water-resistance tests were performed according to AATCC Test Method 42-200 (Water Resistance: Impact Penetration Test) and all samples proved to be waterproof.

\subsection{Scanning Electron Microscopy Results}

Two different fabrics of the study were characterized using SEM instrument to reveal their morphology, coating or lamination structure and information about layers comprising the multi-layered structure. The following 2 fabrics were selected because they represent all fabrics examined within the study in terms of production technique and material type.

\section{Basic Hydrophilic (PTFE Coated Fabric)}

This fabric is a PTFE coated composite and comprised of three layers of fabric (polyester warp and filling), PTFE coating and an extra layer as shown in Figure 7 (carbon-containing repellent material).

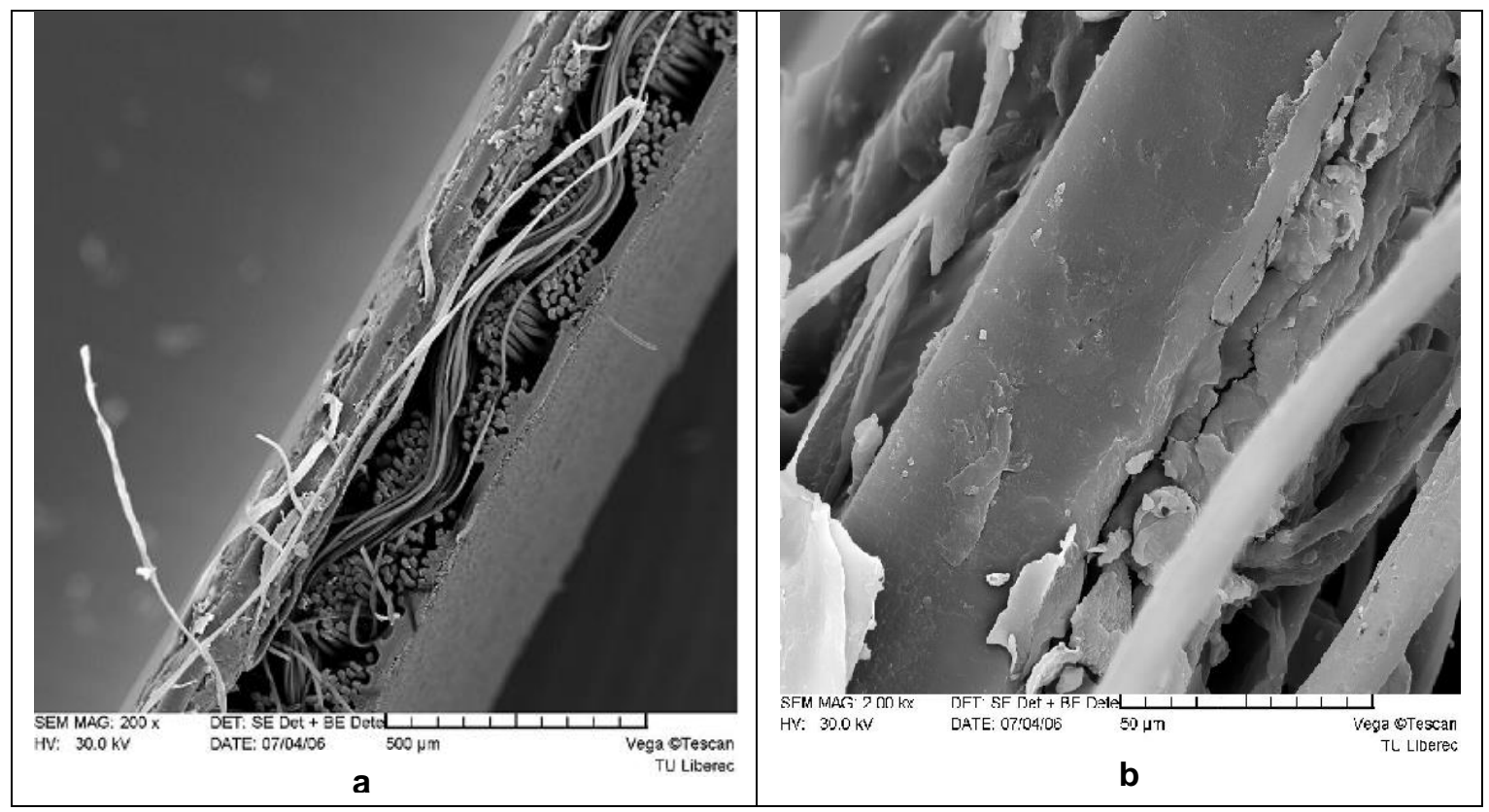

Figure 7. Cross-section image of PTFE coated fabric ( $a: 200 x$ and $b: 2 \mathrm{kx}$ )

Table 3. Thickness of PTFE Coated Fabric and the composite structure

\begin{tabular}{|c|c|c|c|c|c|}
\hline $\begin{array}{c}\text { Thickness of } \\
\text { PTFE } \\
\begin{array}{c}\text { Coating } \\
(\mu \mathrm{m})\end{array}\end{array}$ & $\begin{array}{c}\text { Fabric (PES) } \\
\text { Thickness } \\
(\mu \mathrm{m})\end{array}$ & $\begin{array}{c}\text { Extra Layer } \\
\text { Thickness }(\mu \mathrm{m})\end{array}$ & $\begin{array}{c}\text { Total } \\
\text { Thickness } \\
(\text { Composite } \\
)(\mu \mathrm{m})\end{array}$ & $\begin{array}{c}\text { Fabric } \\
\text { Density } \\
(\text { ends } \times \text { picks } \\
/ \mathrm{cm})\end{array}$ & $\begin{array}{c}\text { Weight } \\
\left(\mathrm{g} / \mathrm{m}^{2}\right)\end{array}$ \\
\hline 47.6 & 224 & 29.4 & 301 & $70 \times 45$ & 185 \\
\hline
\end{tabular}


This fabric has approximately $40 \%$ water vapour transmission rate and $4.6 \operatorname{Ret}\left(\mathrm{m}^{2} \cdot \mathrm{Pa} \cdot \mathrm{W}^{-1}\right)$ water vapour resistance value according to ISO 11092. As it is seen on SEM images, it consists of 3 layers. When the Figure 7 was investigated, it is easily understood that the shape and thickness of the coating polymer. Table 3 also gives information about the details of the layers. When figure analysed, it is apparent that the coating layer in PTFE Coated Fabric is respectively thicker in comparison to the membrane layer in PTFE Laminated Fabric and this leads to a decrease in water vapour permeability value.

\section{Teflon (PTFE Laminated Fabric)}

This fabric is a PTFE laminated composite and comprised of three layers of fabric (polyester warp and filling), PTFE membrane and an extra layer as shown in Figure 8 (carbon-containing repellent material).

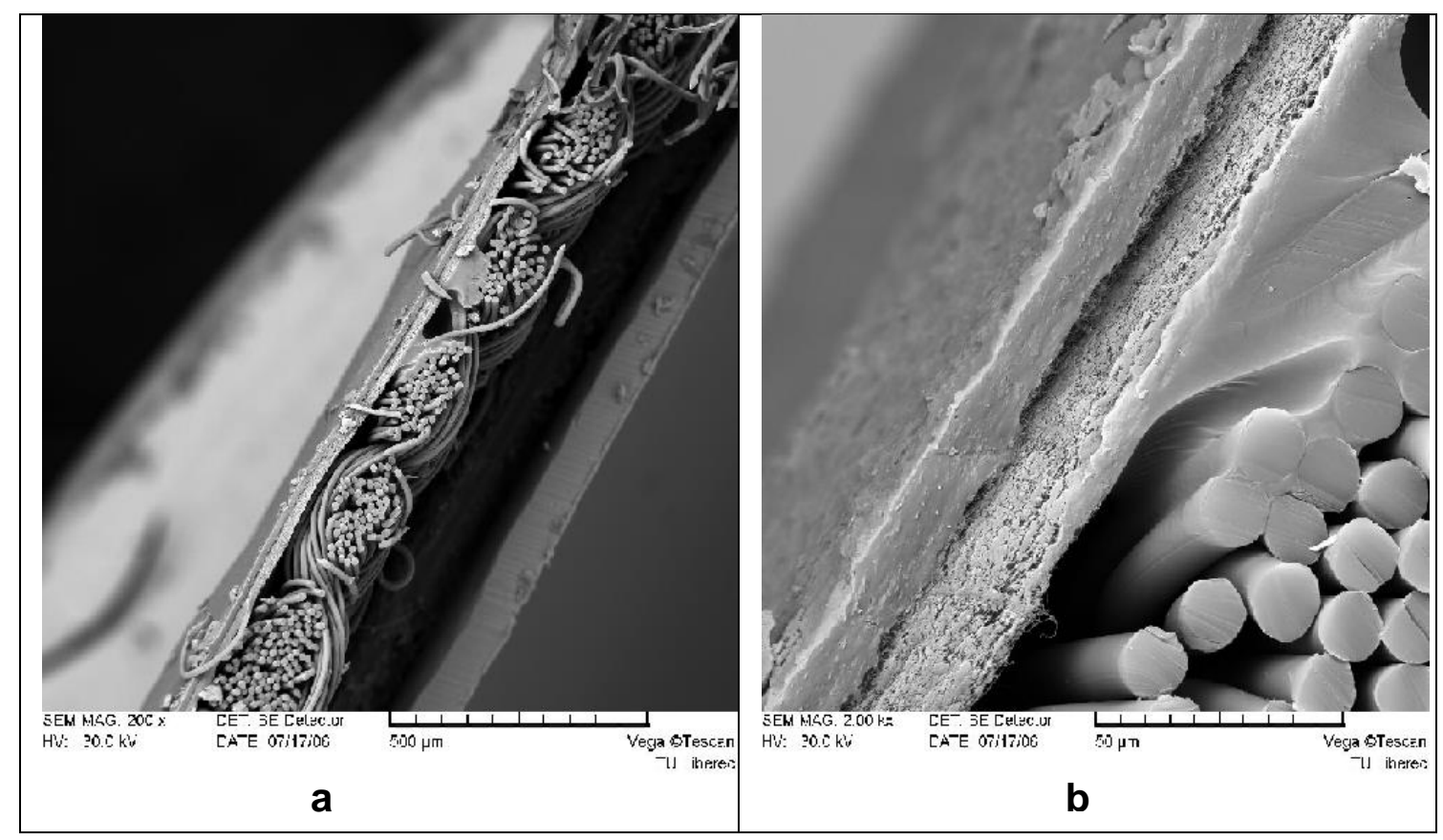

Figure 8. Cross-section image of PTFE laminated fabric ( $a$ : $200 x$ and $b: 2 \mathrm{kx}$ )

Table 4. Thickness of laminated fabric and thickness of composite structure

\begin{tabular}{|c|c|c|c|c|c|}
\hline $\begin{array}{c}\text { Thickness of } \\
\text { PTFE } \\
\begin{array}{c}\text { Membrane } \\
(\mu \mathrm{m})\end{array}\end{array}$ & $\begin{array}{c}\text { Fabric } \\
\text { Thickness } \\
(\mu \mathrm{m})\end{array}$ & $\begin{array}{c}\text { Extra Layer } \\
\text { Thickness }(\mu \mathrm{m})\end{array}$ & $\begin{array}{c}\text { Total } \\
\text { Thickness } \\
(\text { Composite } \\
)(\mu \mathrm{m})\end{array}$ & $\begin{array}{c}\text { Fabric } \\
\text { Density } \\
(\mathrm{ends} \times \text { picks } \\
/ \mathrm{cm})\end{array}$ & $\begin{array}{c}\text { Weight } \\
\left(\mathrm{g} / \mathrm{m}^{2}\right)\end{array}$ \\
\hline 11.1 & 164 & 19.2 & 194.3 & $60 \times 40$ & 123 \\
\hline
\end{tabular}

This fabric has approximately $63.8 \%$ water vapour transmission rate and $2.658 \operatorname{Ret}\left(\mathrm{m}^{2} \cdot \mathrm{Pa} \cdot \mathrm{W}^{-1}\right)$ water vapour resistance value according to ISO 11092. As it is seen on SEM images, it consists of 3 layers. When Figure 8 was investigated, it is easily understood that the shape and thickness of the laminated PTFE membrane. Table 4 also gives information about the details of the layers. When figure analysed, it is apparent that the membrane layer in PTFE Laminated Fabric is remarkably thinner in comparison to the coating layer in PTFE Coated Fabric and this leads to an increase in water vapour permeability value and makes this fabric highly breathable. 


\subsection{Results Obtained Using Ring Apparatus for Simulating the Effect of Air Gap Between Body and Clothing on Water Vapour Permeability Measurement}

Figure 9 shows that as the air gap increases between body and clothing, resistance (Ret) increases and water vapour permeability decreases. In this figure, permeability fits a polynomial function. Normally, water vapour permeability results fit linear function in traditional measurements as the sample tightly placed on the measurement head of the instrument. However, in this measurement, a ring apparatus placed for creating an air gap between the sample and measurement head. As an air gap has been created between sample and measurement head, the resistance against water vapour permeability increased and airflow within this gap fluctuated permeability values obtained so it has followed an anomalous trend fitting a polynomial function. This result provides useful information for the design of high-performance materials in terms of determining the ideal air gap (or air layer in other words) between the wearer's body and clothing. In the above-mentioned study that was carried out by Ruckman, a similar finding was obtained and the author reported that the water vapour transfer rate decreases as the air gap increases. But the author set the air gaps from the water surface and did not share any information regarding the shape or design for the air gap making apparatus. However, the present study has set the air gaps from a dry measuring head and the design of the ring apparatus has been described clearly.

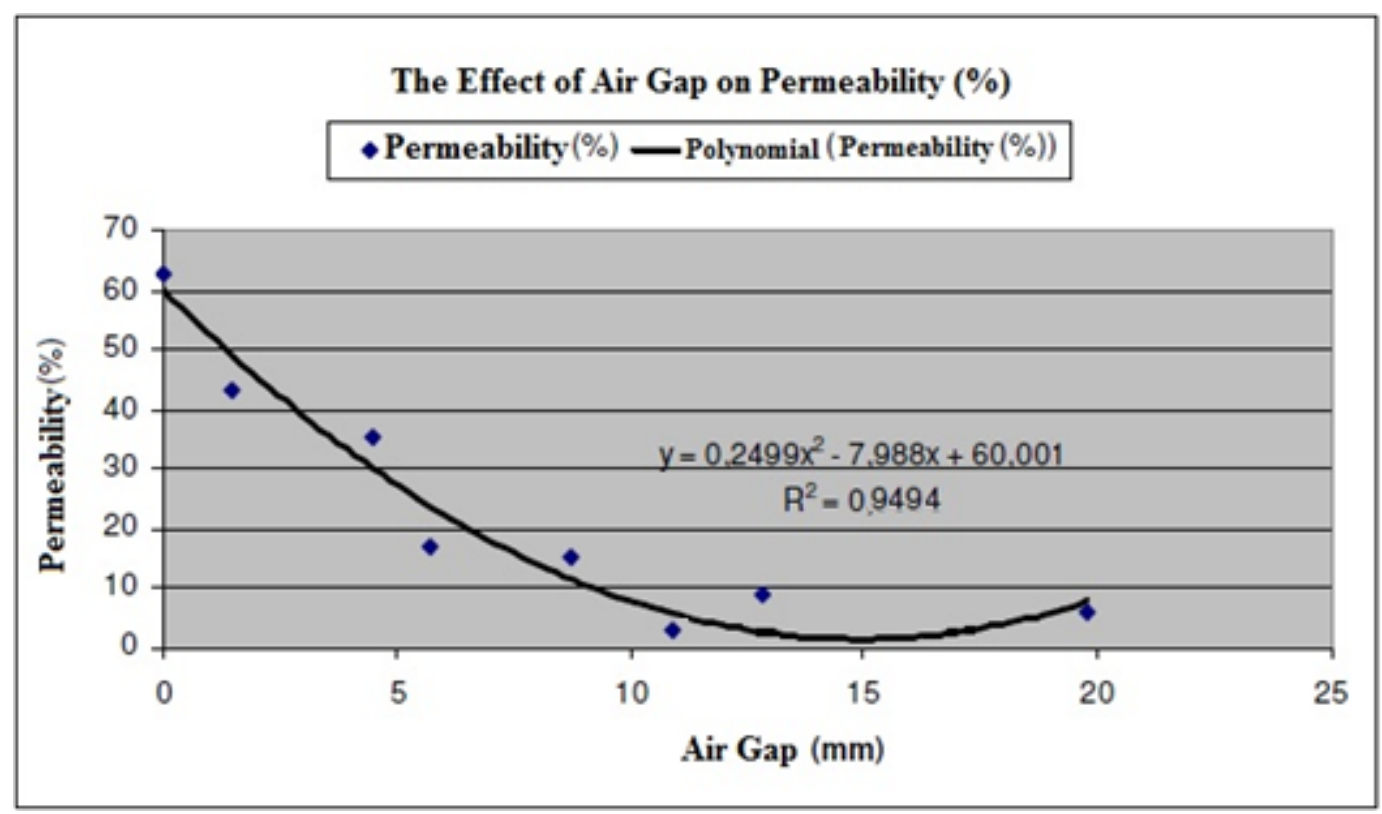

Figure 9. The effect of air gap on water vapour permeability

\section{RESULTS}

With its $2.35 \%$ water vapour permeability, Basic Microporous had the lowest vapour permeability among the samples while having the highest Ret value of 32.038 among the samples. On the contrary, Teflon (PTFE membrane laminated) fabric with its $63.8 \%$ water vapour permeability, had the highest water vapour permeability among the samples while having the lowest Ret value of 2.658 .

One of the most important results obtained in the study is the gap between the clothing and the body has been found to have an important effect on water vapour permeability. For this purpose, the 3 equal width plastic rings were designed according to drawings and the gap between the body and the garment has been successfully simulated. The transmission of water vapour was successfully carried out through the aforementioned rings that are placed between measuring head and fabric, it was found that water vapour permeability decreases as the gap increases and water vapour resistance increases on the contrary.

None of the semi-permeable surfaces had air permeability. The reason for this is that the air molecule is larger than the water vapour molecule and all fabrics examined have pore sizes that are impermeable to the air molecule. 
No water transfer from one side of the surface to the other side of the semi-permeable fabrics was observed for all samples.

When a direct comparison was carried out between Basic Hydrophilic and Teflon Fabric, the utilization of PTFE polymer as a coating in Basic Hydrophilic and as a lamination (membrane) in Teflon fabric created a dramatic difference in terms of water vapour permeability. Waterproof PTFE polymer coating thickness of $47.6 \mu \mathrm{m}$ in Basic Hydrophilic fabric has created a big difference in water vapour resistance in comparison to Teflon fabric having PTFE laminated as a membrane of $11.1 \mu \mathrm{m}$ thickness; Teflon Fabric with thinner (more than 4 times) membrane has performed 1.5 times more water vapour permeability.

In all samples except for Basic Microporous fabric, the fabrics laminated with a membrane showed higher water vapour permeability than that of the coated fabrics.

As of suggestions for future studies according to these results, in the selection of an ideal type of fabric to be used in the design of breathable waterproof structures, it was found that the breathable membrane character, application method of membrane or polymer layer to the main fabric such as lamination/coating, the air gap between body and clothing, the thickness of the clothing assembly are important issues to be considered. For example, in ski jackets, the locations of the zippers that are put in different regions should be determined according to the different sweating areas of the body, the critical number should not be exceeded unless necessary, breathing mechanism should be membrane-based for higher performance and finally the total thickness of jacket assembly should be as light as possible.

\section{CONFLICTS OF INTEREST}

No conflict of interest was declared by the author.

\section{REFERENCES}

[1] Paul, R., High Performance Technical Textiles, Wiley, New Jersey, USA, (2019).

[2] Sivri, Ç., Investigation of Comfort Characteristics of Breathable Fabrics Laminated by a Membrane, M.Sc. Thesis, Suleyman Demirel University Institute of Science and Technology, Isparta, 1-106, (2008).

[3] Holmes, D.A., Waterproof, Breathable Fabrics, In: Handbook of Technical Textiles (Horrocks, A.R., Anand, S.C.), The Textile Institute, Bolton, (2001).

[4] Hunter, L., Fan, J., "Waterproofing and Breathability of Fabrics and Garments", Engineering Apparel Fabrics and Garments, Woodhead Publishing, Sawston, UK, (2009).

[5] Internet, Website, http://www.sympatex.com/index.php?id=48\&L=2. Access date:12.03.2020

[6] Fung, W., "Coated and Laminated Textiles", The Textile Institute, Woodhead Publishing Limited, Cambridge, UK, (2002).

[7] Kaplan, S., Okur, A., "Effects of Heat and Mass Transfer Mechanisms in Textile materials on Clothing Thermal Comfort", The Journal of Textile and Engineer, 13(63): 28-36 (2006).

[8] Classen, E., "Comfort Testing of Textiles, Advanced Characterization and Testing of Textiles", The Textile Institute, Woodhead Publishing Limited, Cambridge, UK, (2018).

[9] Bartels, V.T, "Physiological Comfort of Sportswear, in: Textiles in Sport (Shishoo, R.)", Woodhead Publishing Limited, Cambridge, UK, (2005). 
[10] Kanjana, S., Nalankilli, G., "Smart, Waterproof, Breathable Sportswear-A Review", Journal of Textile and Apparel, Technology and Management, 10(3): 1-13, (2018).

[11] Razzaque, A., Tesinova, P., Hes, L., "Enhancement of Hydrostatic Resistance and Mechanical Performance of Waterproof Breathable Laminated Fabrics", Autex Research Journal, (2018). DOI: $19.10 .1515 /$ aut-2018-0015

[12] Huang, J., Qian, X., "A New Test Method for Measuring the Water Vapour Permeability of Fabrics", Measurement Science and Technology, (2007). DOI: 18.3043.10.1088/09570233/18/9/040

[13] Yanez, J., Farina, J., Rodriguez-Andina, J.J., Poza, F., Magallanes, A., Design and Development of a Waterproof Garment Testing System, (2006). DOI: 3008 -3013.10.1109/ISIE.2006.296095

[14] Hes, L., Dolezal, I., Baczek, M., "Recent Developments in Friendly and Non-destructive Testing of Comfort Properties of Textile Fabrics and Garments, In: Engineering and methodology of modern technology (Paraska, G., and Kowal, J.)", Khmelnytsky National University, Khmelnytskyi, Ukraine, (2012).

[15] Dolezal, I., Hes, L., Bal, K., “A Non-destructive Single Plate Method for Measurement of Thermal Resistance of Polymer Sheets and Fabrics", International Journal of Occupational Safety and Ergonomics, 25(4): 562-567, (2019).

[16] Senthilkumar, M., Kumar, A., Keerthana, A., Pavithra, V., Poongodi, S., "Design and Development of an Instrument for Non-destructive Fabric Weight Measurement", Indian Journal of Fibre and Textile Research, 40: 329-333, (2015).

[17] Hes, L., "Non-destructive determination of comfort parameters during marketing of functional garments and clothing", Indian Journal of Fibre \& Textile Research, 33: 239-245, (2008).

[18] Stoffberg, M. E., Hunter, L., Botha A., "The Effect of Fabric Structural Parameters and Fiber Type on the Comfort-Related Properties of Commercial Apparel Fabrics", Journal of Natural Fibers, 12(6): 505-517, (2015).

[19] Arabuli, S., Vlasenko, V., Havelka, A., Kus, Z., "Analysis of Modern Methods for Measuring Vapor Permeability Properties of Textiles", 7th International Conference - TEXSCI 2010, September 6-8, Liberec, Czech Republic.

[20] Kaynaklı, O., Karadeniz, R., "Isıl Konfor İçin Gerekli Vücut Sıcaklıkları ve Ortam Şartları”, Gazi University Journal of Science, 16(2): 327-338, (2003).

[21] Huang, J., "Review of heat and water vapor transfer through multilayer fabrics", Textile Research Journal, 86(3): 325-336, (2016).

[22] Ruckman, J.E., "Water vapour transfer in waterproof breathable fabrics-Part 2: under windy conditions", International Journal of Clothing Science and Technology, 9(1): 23-33, (1997).

[23] Razzaque, A., Tesinova, P., Hes, L., Salacova, J., Abid, H.A., "Investigation on Hydrostatic Resistance and Thermal Performance of Layered Waterproof Breathable Fabrics", Fibers and Polymers, 18(10): 1924-1930, (2017).

[24] TS EN ISO 11092 Measurement of thermal and water-vapour resistance under steady-state conditions. 
[25] Hes, L., Non-destructive determination of comfort parameters during marketing of functional garments and clothing", Indian Journal of Fibre \& Textile Research, 33: 239-245, (2008).

[26] TS 391 EN ISO 9237 Textiles-Determination of Permeability of Fabrics to Air.

[27] AATCC 42-200 Test Method for Water Resistance: Impact Penetration.

[28] Ruckman, J.E., "Water vapour transfer in waterproof breathable fabrics-Part 1: under steady-state conditions", International Journal of Clothing Science and Technology, 9(1): 10-22, (1997). 